\title{
A ELITE DA POLÍTICA PARANAENSE COMPOSIÇÃO, LÓGICAS DE RECRUTAMENTO E VALORES DEMOCRÁTICOS
}

\author{
Camila Lameirão
}

O regime democrático, segundo Giovanni Sartori (1994), produz minorias, no plural, que executam funções de liderança e direção no sistema político. Assim, a idéia de que uma sociedade democrática é governada por um único grupo coeso, como supunha Wright Mills (1981) em sua análise sobre a elite norte-americana, não pode ser comprovada. Empiricamente, na visão de Sartori, "as democracias são caracterizadas pela difusão do poder”, em que diversos grupos, antagônicos ou não, por meio de procedimentos de seleção e escolha, podem alcançar a capacidade de mando. De acordo com o autor italiano, a democracia pode ser descrita como um "modelo de liderança de minorias caracterizado pela multiplicidade de grupos de poder entrecruzados e envolvidos em manobras de coalizão" (SARTORI, 1994, p. 203).

Comumente, atribui-se a essas minorias, que exercem alguma função ou cargo político, a denominação de elite. Para ser melhor examinado, cumpre destacar que o termo elite envolve duas dimensões, uma conceitual e outra empírica. O plano conceitual refere-se à definição do que é a elite, suas características e identificação, definindo-a em uma estrutura e/ou tipologia. Quanto à dimensão empírica, consiste em verificar quem é a elite, isto é, se ela existe realmente e quem tem o controle do quê. Acima de tudo, essa dimensão é fundamental para mostrar qual elite existe e se está de acordo com a definição conceitualmente estabelecida. Nesse sentido, ter a noção de quem é a elite política é uma tarefa imprescindível para saber quais elites compõem uma dada democracia e quão democrático é um regime.

No Brasil, pouco a pouco, estudos sobre a dimensão empírica das elites têm ganhado espaço, posto que desde a redemocratização em 1985 vêm surgindo no campo das ciências sociais algumas pesquisas e análises sobre o perfil e a composição dos grupos que integram instituições como a Assembléia Constituinte (RODRIGUES, 1987), a Câmara dos Deputados (SANTOS, 1997; RODRIGUES, 2002; MIGUEL, 2003; CORADINI, 2007) ministérios e agências do governo federal (LOUREIRO, ABRUCIO \& ROSA, 1998a; 1998b; D’ARAUJO, 2007; OLIVIERI, 2007), partidos políticos (MENEGUELLO, 1989; RODRIGUES, 1989; AMARAL, 2007), entre outras. A partir desses estudos vem sendo possível identificar e conhecer parte da elite do país. Entretanto, tais trabalhos constituem um esforço analítico ainda incipiente nas ciências sociais, posto que sua consolidação em um campo de pesquisa de destaque em congressos acadêmicos e produções bibliográficas parece, por ora, restrita, apesar de na área da ciência política esse ramo vir avançando consideravelmente nos últimos anos.

A publicação do livro Quem governa? sob a coordenação de Renato Perissinotto, Adriano Codato, Mário Fuks e Sérgio Braga constitui uma contribuição de peso e um marco relevante para essa linha de pesquisa em via de consolidação, pelo fato de ser um esforço de análise de três diferentes elites que compõem o sistema político brasileiro: a elite político-administrativa, a parlamentar e a partidária, além de ter como objeto um governo subnacional, o do estado do Paraná. Esse último ponto merece ser destacado já que se constitui numa iniciativa valorosa em meio a um campo de pesquisa em que predominam trabalhos focados no âmbito federal. Como se vê nas referências bibliográficas apontadas acima, o estudo sobre as elites políticas, tanto do poder Legislativo como do Executivo, concentra-se na esfera do governo federal.

Esse livro é uma coletânea de artigos desenvolvidos no âmbito de um mesmo projeto, levado a cabo por pesquisadores do departamento de Ciência Política da Universidade Federal do Paraná, cuja principal proposta consistia em produzir um mapeamento do grupo que conduziu a política paranaense nos últimos anos. $\mathrm{O}$ objetivo era conhecer quem governa especificamente no período da gestão do Governador Jaime Lerner (Partido da Frente Liberal (PFL), atual Democratas (DEM)), abrangendo os anos de 1995 a 2002, isto é, seus 
dois mandatos. Para tanto, investigaram alguns secretários do Governador, deputados estaduais (das $13^{\mathrm{a}} \mathrm{e} 14^{\mathrm{a}}$ legislaturas) e presidentes regionais dos partidos políticos. No total, os pesquisadores trabalharam com uma amostra de 108 pessoas de um universo de 174, o que equivale a uma abrangência de 62\% desse grupo.

O trabalho está organizado em quatro partes temáticas: a primeira trata da origem social das três elites analisadas; em seguida abordam-se suas fontes de recrutamento político e profissional; e na terceira parte temse como foco os valores e as concepções desses grupos sobre a democracia. Por fim, apresentam-se alguns estudos de caso que dão conta da dinâmica de funcionamento da Assembléia Legislativa paranaense no período estudado, bem como de suas relações com o governo, a mídia e a sociedade civil. Quanto à metodologia, o livro é bastante criterioso, e por esse mérito tem as condições de lançar as bases metodológicas e analíticas que podem orientar a produção futura de trabalhos similares nesse campo de estudo. Contando com uma seção introdutória na qual a metodologia utilizada na pesquisa é explicada, tem-se logo de início uma noção dos procedimentos de coleta dos dados e a forma como eles foram organizados e classificados. Quem governa? privilegia uma metodologia quantitativa para a obtenção dos dados, que se deu por meio da técnica do survey por meio da aplicação de questionários, mas sua dimensão qualitativa também recebe minuciosa atenção. Isso se torna evidente pela disposição dos autores em dar sustentação teórica ao estudo sobre as elites políticas a partir de um enfoque que privilegia a dimensão da cultura política na compreensão da estrutura de poder em uma democracia. Assim, o trabalho apresenta uma perspectiva teórica que não se resume apenas aos aspectos formais das instituições políticas, mas lança luz sobre dimensões sociais, culturais e comportamentais da realidade política, por meio da pesquisa empírica sobre a elite do poder.

Ao longo dos capítulos, os autores fazem referência ao debate entre "culturalistas" e "institucionalistas" que perpassa o objeto da pesquisa, cujo ponto de divergência refere-se às condições que asseguram a operacionalização e a estabilidade do regime democrático. Na perspectiva dos culturalistas, grosso modo, a democracia gozaria de estabilidade uma vez que os valores e as idéias das elites governantes refletissem zelo e preferência por este regime. Por outro lado, para os institucionalistas, as instituições teriam um papel central na explicação do caráter estável de uma democracia, pois os atores estariam a todo tempo submetidos a constrangimentos institucionais, por meio de regras e dispositivos de ação, que os induziriam a acatar e manter o regime democrático. É importante destacar que essa discussão tem um ponto de partida sociológico que busca investigar o raio de ação dos atores, isto é, se suas ações são explicadas por condicionantes de diversas naturezas, ou se, sobrepondo-se a esses condicionamentos, causam por si impactos na realidade. Nesse sentido, o estudo sobre o perfil das elites constituiria um meio oportuno para avaliar em que medida essas elites aderem à democracia e "importam" para sua operacionalização e para os resultados que a democracia produz. A partir desse enfoque, levantar-se-iam as seguintes questões: diferentes elites possuiriam a capacidade de operar a democracia de diferentes formas? Ou, diferenças entre as elites teriam pouca importância, uma vez que as instituições do regime democrático restringiriam, ou anulariam, o espaço das ações e dos projetos das elites, ensejando distintos grupos a seguir quase sempre o mesmo roteiro?

Embora o livro não responda a essas indagações, e nem seja, ao que parece, sua intenção fazê-lo, ele nos oferece alguns elementos para compreender os contornos que as elites políticas dão ao regime democrático. Procedendo na análise dos atributos sociopolíticos, profissionais e ideológicos que caracterizam as elites sob investigação, o livro apresenta um retrato sobre "quem são", "de onde vêm” e "qual a visão de mundo" dos grupos que compõem os três núcleos de poder do sistema político paranaense: o governo, o poder Legislativo e os partidos políticos. Com essa análise procura-se avaliar quão homogênea eram as elites que integravam as principais instituições políticas do Paraná no período de 1995-2002, e assim identificar as características definidoras dos padrões de recrutamento que mediaram o acesso desses grupos aos cargos de mando no estado.

Os autores observam, sobretudo no decorrer da primeira parte do livro, que as elites político- administrativa, parlamentar e partidária definem-se por atributos sociais similares: a maioria de seus membros é composta por homens, brancos, católicos e pertencentes ao estrato social médio-alto, além de terem formação predominantemente nas áreas de direito e engenharia. Contudo, há uma maior diversidade quando se trata da escolaridade e da trajetória profissional dessas elites. Os secretários de governo têm alto nível escolar, aproximadamente $90 \%$ possuem nível superior ou pós-graduação, sendo que $61 \%$ formaram-se em direito ou engenharia, e praticamente três quartos deles eram profissionais liberais e funcionários públicos antes de assumirem o cargo no governo. Quanto aos deputados estaduais, apenas uma reduzida maioria, cerca de 56\%, têm alta escolaridade, cuja formação deu-se predominantemente na área do direito (43\%). Ademais, essa elite apresenta 
uma heterogeneidade significativa quanto ao tipo de ocupação, de modo que apenas $17 \%$ dos deputados entrevistados eram políticos antes de ocuparem o cargo que ocupavam no período da pesquisa. Os presidentes dos partidos, por sua vez, possuem um alto nível escolar (80\%), sendo que $73 \%$ formaram-se em direito ou engenharia, e caracterizam-se pelo seguinte tipo de ocupação: 35,7\% eram profissionais liberais e 42,8\% altos funcionários públicos e políticos.

Na segunda parte do trabalho o objetivo principal é averiguar a trajetória política e/ou profissional dos componentes das três elites consideradas na análise. Tem-se, com isso, o propósito de avaliar se há determinadas condições e atributos a serem preenchidos para que os indivíduos alcancem essas posições de mando. Em outras palavras: procura-se mostrar se existe um padrão que defina o modo de acesso aos postos dessas três elites. Observou-se que as formas de recrutamento para as elites político-administrativa e partidária apresentam, cada uma, exigências específicas, diferentemente do que ocorre com o grupo parlamentar cuja trajetória política e/ou profissional não se enquadra em um padrão. Esse último dado deve ser salientado, pois a escolha dos parlamentares é feita num universo muito maior do que naqueles nos quais são selecionados os secretários do Governador e os presidentes dos partidos. Desse modo, suas fontes de recrutamento possivelmente são diversificadas, e, por isso, estão menos suscetíveis a obedecer a um mesmo critério de seleção.

Os dados referentes à carreira dos secretários do governo Lerner mostram que 91\% tiveram passagem pelo setor público antes de ingressar no governo, por meio de concurso ou nomeação para cargos no âmbito municipal ou estadual, revelando ser alta a perícia gerencial desse grupo no aparato estatal. Por outro lado, a inserção stricto sensu dessa elite na política é, na visão dos autores, bastante superficial, uma vez que não se caracteriza pela competição em cargos eletivos. Além disso, sua vinculação partidária, embora considerável, pois $66,7 \%$ dos secretários indicaram filiação a partidos políticos, parece ser mais bem explicada, segundo os autores, pela fidelidade ao governador Lerner do que por qualquer agremiação ou ideologia política. No que tange à elite dos presidentes de agremiações partidárias, observou-se que é composta por pessoas com extensa experiência em cargos públicos eletivos, no âmbito legislativo, inclusive na esfera do governo federal, e que já possuíam experiência de direção partidária, o que leva a crer que a ocupação desses cargos exige a obtenção de "capitais" conquistados ao longo de anos de experiência política nos quais são construídas a reputação desses quadros e suas alianças de apoio. Por fim, vale dizer que os deputados estaduais constituem o grupo cuja trajetória apresenta diferenças mais significativas: há variação quanto ao tempo da carreira política, ao percurso político (ou seja, se a carreira política deu-se no poder Legislativo, no Executivo ou em ambos), à ocupação de cargos de direção partidária e às vinculações institucionais e sociais dos parlamentares. De certa forma, essas diferenças poderiam ser explicadas considerando a diversidade das fontes de recrutamento da Assembléia Legislativa, uma vez que, dependendo dos segmentos sociais e profissionais a que pertencessem os deputados estaduais, antes de assumirem seus respectivos mandatos, eles possuiriam experiências e inserções políticas diferentes que distinguiriam suas trajetórias. Esse fato tem a ver com a própria natureza representativa da instância legislativa que supõe a presença de representantes de diferentes segmentos da sociedade, cujo perfil e trajetória estariam vinculados, em parte, às características da sua base eleitoral.

As partes I e II do livro possibilitam o entendimento das lógicas de recrutamento que definem a composição dos grupos político-administrativo, parlamentar e partidário, e também da estrutura da elite política paranaense (ou seja, a relação específica que se estabelece entre os diferentes setores que compõem essa elite). Quanto às formas de recrutamento, considerando os atributos sociais e político-profissionais, o livro revela que cada elite tem um espaço de socialização e treinamento próprios que condicionam a sua ascensão aos postos políticos e tem a ver com a função a ser desempenhada. Embora não se trate de um padrão estruturado de recrutamento, dado que subsistem algumas diferenças no interior de cada elite, identifica-se que há sim condições que são requeridas para a ocupação dos respectivos cargos, como, por exemplo, no que toca à elite administrativa, o fato de possuir experiência em cargos públicos e formação técnica. Nesse sentido, conforme observado pelos autores, esses "espaços de socialização" específicos a cada grupo configuram uma estrutura que restringe o trânsito entre as elites, isto é, a possibilidade de essas pessoas exercerem, ao decorrer de sua trajetória, cargos em outros segmentos de elite. Essa constatação pode ser entendida como uma evidência da institucionalização dos critérios que regem o acesso das elites às distintas esferas da política, revelando as regras e os procedimentos específicos que definem a composição dos espaços burocrático-administrativo, legislativo e partidário de um sistema político. A identificação de lógicas de recrutamento diferentes entre os três segmentos analisados mostra que o ingresso nos postos de mando não se dá aleatoriamente, mas sob o cumprimento de algumas condições específicas, que restringem um livre deslocamento entre os grupos que estão no poder. 
Entretanto, embora haja a constatação de que esses grupos não costumam transitar pela esfera política um dos outros, na terceira parte do livro apresentam-se dados referentes aos valores e às concepções sobre a democracia dessas três elites, que mostram que em termos ideológicos há proximidades entre elas, evidenciando traços de homogeneidade que perpassam os três núcleos de poder. Ao decorrer dos capítulos que compõem essa parte, os autores procuram avaliar o nível de adesão dos três grupos ao regime democrático e aferir o modelo de democracia (procedimental ou participativo) bem como os tipos de políticas públicas que defendem. Observou-se que a intensa adesão ao regime democrático parece ser uma tendência das elites políticas, que maciçamente apontaram-na como a melhor forma de governo. Contudo, parcelas significativas dos grupos político-administrativo e parlamentar indicaram que em algumas situações (como a ameaça generalizada à propriedade privada ou o descontrole da corrupção) concordariam com a suspensão da democracia, o que os contrasta com a elite partidária cuja aceitação do fim do regime, em alguma das condições apontadas pelos pesquisadores, é mínima. Interessante notar que as elites parecem ter concepções próximas acerca da democracia, uma vez que compartilham a visão de que o voto constitui o principal instrumento de participação dos cidadãos nesse regime, em detrimento dos mecanismos mais diretos de intervenção popular na prática política, como plebiscitos, orçamento participativo e conselhos gestores. Apenas o grupo parlamentar demonstra um apoio majoritário, embora bastante fragmentado, a essas práticas participativas. Com isso, os autores constatam que esses grupos comungam a adesão a um modelo procedimental de democracia que circunscreve ao voto a oportunidade de participação popular. Cumpre ressaltar que essa concepção minimalista do regime democrático, que orienta a visão de mundo desses três grupos, apresenta coerência com as políticas públicas que defendem, na medida em que se verificou um apoio mínimo, sobretudo entre as elites do governo e do poder Legislativo, justamente àquelas que atuam na produção de políticas públicas como as políticas igualitárias mais radicais (como as “cotas para negros em universidades públicas” e a "reforma agrária”). Por sua vez, é forte a adesão à "universalização da saúde pública” e ao "sistema universitário gratuito", que constituem políticas clássicas do Estado de Bem-estar, as quais tendem a restringir o raio da ação estatal a funções básicas de assistência aos cidadãos.

Com essa terceira seção, os autores encerram a parte do livro referente à descrição dos atributos sociopolíticos, profissionais e ideológicos dos grupos sob análise. Segue-se, então, a última seção em que são apresentados três estudos de caso que contextualizam e descrevem algumas dinâmicas do processo de governo paranaense durante os anos de 1995 a 2002. Vale dizer que, ao enfocar a dimensão comportamental dos três setores da elite, essa última parte do livro dialoga com as demais no sentido de oferecer uma oportunidade para se entender alguns aspectos da forma como esses grupos operacionalizaram a democracia durante o período de investigação da pesquisa. Os autores justificam a opção pelo método de estudo de caso por considerá-lo mais adequado à proposta de "capturar" os processos constitutivos da relação entre o poder Executivo e o Legislativo, levando em conta as estratégias, recursos e esquemas de ação dos atores envolvidos nos processos decisórios.

Ao longo dessa parte final, os autores narram acontecimentos e apresentam dados empíricos que revelam dimensões pouco conhecidas da política estadual do Paraná, como o peso do poder Legislativo no processo decisório, o potencial de mobilização dos grupos organizados da sociedade civil, e as coalizões que podem emergir entre esses setores e os membros do Legislativo estadual em torno de questões conflituosas, como no caso da eminência de privatização da Copel (Companhia de Energia Elétrica do Paraná), em 2001. A partir das informações levantadas pelos pesquisadores, atestou-se que os deputados estaduais foram responsáveis pela maioria das "leis relevantes" (que tratam de assuntos de maior impacto alocativo e social), e por cerca de $80 \%$ dos projetos de lei de maior alocação aprovados na $14^{\mathrm{a}}$ Legislatura (1999-2003). Outra evidência apresentada sobre o papel relevante da instância legislativa na política paranaense refere-se ao processo de privatização da Copel, no qual os deputados contrários a essa medida forjaram uma ampla aliança, incluindo grupos da sociedade civil e políticos de outras esferas de governo, e formaram um movimento de pressão que transcendeu às instituições políticas formais. Nesse episódio, os parlamentares foram hábeis em mobilizar a população e a opinião pública, o que os levou a conseguir fazer valer sua posição e impor uma derrota ao poder Executivo.

Vale dizer que esses padrões de ação do poder Legislativo paranaense poderiam por si só relativizar a difundida idéia de que a política brasileira caracteriza-se pela predominância do Executivo vis-à-vis o Legislativo, sobretudo no âmbito subnacional de governo, que deu margem ao termo "ultrapresidencialismo estadual" (ABRÚCIO, 2002). Seria oportuno também atentar que tanto a participação, constatada pelos autores, dos deputados na produção legislativa relevante do estado (sobretudo, no âmbito de políticas sociais) como a sua capacidade de aliar-se à população, instigando a sua mobilização, podem ser vistas como formas pelas quais os 
parlamentares buscariam maximizar seus recursos e oportunidades de ação. Ou seja, mediante as restrições institucionais e de poder sob as quais operam em relação ao poder Executivo, os legisladores escolheriam estrategicamente meios de ação que fossem mais efetivos no cumprimento de seus objetivos, uma vez que "a maximização racional do próprio interesse corresponde mais de perto à realidade da ação política, leiga e competitiva, do que as alternativas do altruísmo, da ideologia ou do espírito cívico” (ANDRADE, 1998, p. 17).

Por fim, é interessante notar a visão e a metodologia alternativas que os autores lançam sobre eventos da vida política, vigentes nos três níveis de governo, que comumente não são focos de análises detalhadas. É o caso, por exemplo, da produção legislativa dos parlamentares, que à primeira vista é tida como clientelista e superficial, mas que muita das vezes revela uma agenda de políticas própria, como destacam os autores: "no tocante à legislação relevante, as agendas entre os poderes também são distintas [...] enquanto a maior parcela da legislação relevante originária do Executivo regula temas administrativos e econômico-financeiros, a maioria relativa das normas gerais originárias do Legislativo trata de temas sociais” (PERISSINOTTO et alii, 2007, p. 264-265). Nesse sentido, o recurso ao método do estudo de caso especifica e qualifica um padrão de atuação parlamentar e possibilita o entendimento de lógicas de ação que podem passar despercebidas, como aquela na qual os deputados estaduais ligam-se estrategicamente a setores da sociedade civil para marcar a sua posição frente ao poder Executivo. Por isso, Quem governa? aborda um tema já estudado pela ciência política brasileira, qual seja, a relação entre os poderes Executivo e Legislativo, mas adota um enfoque alternativo que permite apreender fenômenos específicos dessa realidade, o que o torna um livro inovador.

Ademais, a sua originalidade deve-se fundamentalmente às suas três primeiras partes que se constituem num mapeamento diverso da elite política paranaense, e cuja conclusão é que, a despeito de alguns atributos que as tornam similares, essas elites “formam grupos específicos, fechados em si mesmos”, já que "um número muito pequeno de indivíduos (apenas quatro em 108) trafegou por diversos segmentos da elite durante o período analisado" (idem, p. 333). Há de se considerar, no entanto, que o fato desses indivíduos não terem ocupado cargos que não fossem em seu universo de atuação (seja no poder Executivo ou no Legislativo) signifique que não tenham ligação uns com os outros e que constituam grupos fechados em si mesmos. No “presidencialismo de coalizão" o pertencimento a redes sociais é a chave para se entender como indivíduos de origens e trajetórias profissionais distintas entrecruzam-se e formam relações pessoais que possibilitam seu acesso ao poder. Assim, burocratas e políticos podem ter ligações que, a olho nu, podem não ser identificadas, mas que a partir, por exemplo, de estudos de casos sejam esclarecidas. Além do mais, categorias analíticas, como a de policy makers, que prescindem de uma abordagem dicotômica na análise da relação entre políticos e burocratas, constituem recursos por meio dos quais é possível entender e perceber o modelo híbrido de atuação desses dois grupos, no qual "os políticos baseiam sua atuação cada vez mais no discurso técnico, e burocratas reforçam o aspecto político em seu cálculo de atuação, seja mediando interesses de clientelas específicas, seja norteando-se pelos sinais emitidos por políticos do Executivo, do Legislativo e de outras esferas de poder" (LOUREIRO, ABRUCIO \& ROSA, 1998a, p. 48). Nesse sentido, a relação entre os ocupantes desses dois segmentos de elite não deve ser vista a partir de uma perspectiva estanque, mas considerando a existência de ligações e confluências que entrecruzam os padrões de ação e os cálculos desses grupos, seja com o objetivo final de constituir coalizões de apoio ou de travar "lutas" que viabilizem o acesso aos recursos de poder. Portanto, esses marcos analíticos ajudariam a complementar e a relativizar algumas conclusões do livro, entre as quais a mencionada acima que atesta o caráter "fechado" e "particular" dos grupos de poder paranaenses, contribuindo para o desenvolvimento dessa agenda de pesquisa sobre as elites políticas para o qual o próprio livro Quem governa? representa uma colaboração inquestionável.

Camila Lameirão (camila_lameirao@yahoo.com.br) é doutoranda em Ciência Política pela Universidade Federal Fluminense(UFF).

\section{REFERÊNCIASBIBLIOGRÁFICAS}

ABRÚCIO, F. 2002. Os barões da federação: os governadores e a redemocratização brasileira. São Paulo : Hucitec.

ANDRADE, R. C. (org.). 1998. Processo de governo no município e no estado: uma análise a partir de São Paulo. São Paulo : USP. 
AMARAL, O. 2007. O crescimento institucional e as transformações do Partido dos Trabalhadores. Paper preparado para o Congresso LASA (Latin American Studies Association), Montreal, Canadá, set.

CORADINI, O. L. 2007. Engajamento associativo-sindical e recrutamento de elites políticas: tendências recentes no Brasil. Revista de Sociologia e Política, Curitiba, n. 28, p. 181-203, jun.

D’ARAUJO, M. C. 2007. Governo Lula: contornos sociais e políticos da elite do poder. Rio de Janeiro : CPDOC.

LOUREIRO, M. R.; ABRUCIO, F. L. \& ROSA, C. A. 1998a. Radiografia da alta burocracia federal brasileira: o caso do Ministério da Fazenda. Revista do Serviço Público, n. 4, p. 46-81, out.-dez.

1998b. Burocracia e política na nova ordem democrática brasileira: o provimento de cargos no alto escalão do governo federal (governo Sarney, Collor, Itamar Franco e FHC). Relatório de pesquisa. São Paulo: FGV.

MENEGUELLO, R. 1989. PT: a formação de um partido: 1979-1982. Rio de Janeiro : Paz e Terra.

MIGUEL, L. F. 2003. Capital político e carreira eleitoral: algumas variáveis na eleição para o Congresso brasileiro. Revista de Sociologia e Política, Curitiba, n. 20, p. 115-134, jun.

OLIVIERI, C. 2007. Política, burocracia e redes sociais: as nomeações para o alto escalão do Banco Central do Brasil. Revista de Sociologia e Política, Curitiba, n. 29, p. 147-168, nov.

PRESISSINOTTO, R. M.; CODATO, A.; BRAGA, S. S. \& FUKS, M. (orgs) 2007. Quem governa? Um estudo das elites políticas no Paraná. Curitiba : UFPR.

RODRIGUES, L. M. 2002. Partidos Políticos, Ideologia e Composição Social. São Paulo : EDUSP. 1989. Partidos e Sindicatos - Escritos de Sociologias Política. São Paulo : Ática.

1987. Quem é Quem na Constituinte. São Paulo : Oesp-Maltese.

SANTOS, F. 1997. Patronagem e Poder de Agenda na Política Brasileira. Dados, Rio de Janeiro, v. 40, n. 3.

SARTORI, G. 1994. A teoria democrática revisitada. I. O debate contemporâneo. São Paulo : Ática.

WRIGHT MILLS, C. 1981. A elite do poder. Rio de Janeiro : J. Zahar. 